\title{
Metabolic engineering of Escherichia coli BL21 (DE3) for de novo production of L-DOPA from D-glucose
}

Eric Fordjour ${ }^{1,2,4}$, Frederick Komla Adipah ${ }^{1,2,4}$, Shenghu Zhou ${ }^{1,2,4}$, Guocheng Du, 2,3* and Jingwen Zhou Z $^{1,2,4^{*}}$ (D)

\begin{abstract}
Background: Production of L-tyrosine is gaining grounds as the market size of 3,4-dihydroxyphenyl-L-alanine (L-DOPA) is expected to increase due to increasing cases of Parkinson's disease a neurodegenerative disease. Attempts to overproduce L-tyrosine for conversion to L-DOPA has stemmed on the overexpressing of critical pathway enzymes, an introduction of feedback-resistant enzymes, and deregulation of transcriptional regulators.

Results: An E. coli BL21 (DE3) was engineered by deleting tyrR, ptsG, crr, pheA and pykF while directing carbon flow through the overexpressing of galP and $g / k$. TktA and PpsA were also overexpressed to enhance the accumulation of E4P and PEP. Directed evolution was then applied on HpaB to optimize its activity. Three mutants, G883R, G883A, L1231M, were identified to have improved activity as compared to the wild-type hpaB showing a 3.03-, 2.9- and 2.56fold increase in L-DOPA production respectively. The use of strain LP-8 resulted in the production of $691.24 \mathrm{mg} / \mathrm{L}$ and $25.53 \mathrm{~g} / \mathrm{L}$ of L-DOPA in shake flask and $5 \mathrm{~L}$ bioreactor, respectively.
\end{abstract}

Conclusion: Deletion of key enzymes to channel flux towards the shikimate pathway coupled with the overexpression of pathway enzymes enhanced the availability of L-tyrosine for L-DOPA production. Enhancing the activity of $\mathrm{HpaB}$ increased L-DOPA production from glucose and glycerol. This work demonstrates that increasing the availability of L-tyrosine and enhancing enzyme activity ensures maximum L-DOPA productivity.

Keywords: L-Tyrosine, 4-Hydroxyphenylacetate 3-monooxygenase, Melanization, Modular expression, Parkinson's disease

\section{Background}

3,4-Dihydroxyphenyl-L-alanine (L-DOPA), an amino acid produced biosynthetically from L-tyrosine, is a precursor to the neurotransmitter dopamine. It has been an essential commodity in the pharmaceutical firms since the 1960s as it is used as a therapeutic agent for dopamine-responsive dystonia and Parkinson's Disease (PD) a neurodegenerative disorder caused by a deficiency in the

\footnotetext{
*Correspondence: gcdu@jiangnan.edu.com;

zhoujw1982@jiangnan.edu.cn

${ }^{1}$ National Engineering Laboratory for Cereal Fermentation Technology,

Jiangnan University, 1800 Lihu Road, Wuxi 214122, Jiangsu, China

${ }^{2}$ Key Laboratory of Industrial Biotechnology, Ministry of Education,

School of Biotechnology, Jiangnan University, 1800 Lihu Road,

Wuxi 214122, Jiangsu, China

Full list of author information is available at the end of the article
}

action and formation of dopamine by the dopaminergic neurons of the brain $[1,2]$. Since L-DOPA is a precursor for dopamine and crosses the blood-brain barrier while dopamine cannot, it is meant to increase the dopamine concentration for the treatment of PD [3, 4]. The chemical synthesis of producing L-DOPA involves a complicated reaction procedure, requiring expensive metal catalysts that work under harsh operational conditions with low substrate specificity $[5,6]$.

With the increasing size in cases of Parkinson's disease not only in the elderly but among the younger generation, the market size of L-DOPA is expected to increase but still stands at 250 ton per year [7]. The biotechnological process involving microbial fermentation serves as a suitable alternative to improve the conversion rate, the enantioselectivity and also economize the 
process [8]. Currently, biotechnological processes for L-DOPA production are based on the enzymatic activity or catalyzation of tyrosine phenol-lyase, tyrosinase, and 4-hydroxyphenylacetate 3-monooxygenase activity. Tyrosinase, a copper-containing enzyme contains two cupric ions in the active regions of the proteins named $C u A$ and $C u B$. This enzyme catalyzes two reactions; the hydroxylation of L-tyrosine to L-DOPA through the cresolate activity and the oxidation of L-DOPA to dopaquinone (catecholase activity) [9]. Tyrosine phenollyase degrades L-tyrosine as a carbon and nitrogen source in bacteria during the reversible catalysis of L-tyrosine to pyruvate, ammonia, and phenol. L-DOPA can be synthesized if pyruvate, ammonia, and catechol are used as starting materials [7]. The use of 4-hydroxyphenylacetate 3-monooxygenase to hydroxylate L-tyrosine for L-DOPA production has also been gaining grounds.

4-Hydroxyphenylacetate 3-monooxygenase from Escherichia coli is a two-component enzyme encode by $h p a B$ and $h p a C$ genes that catalyzes the degradation of 4-hydroxyphenylacetate (4-HPA) through the introduction of a second hydroxyl group into the benzene nucleus at a position ortho to the existing hydroxyl group to yield 3,4-dihydroxyphenylacetate (3,4-DHPA) [10, 11]. In a recent study by Xun and Sandvik, they showed that in the absence of $h p a B, \mathrm{FADH}_{2}$ was quantitatively autoxidized to $\mathrm{H}_{2} \mathrm{O}_{2}$ whereas the $\mathrm{FADH}_{2}$ utilization by $h p a B$ is slightly faster than the autoxidation [12]. The enzyme is known to have a broad substrate spectrum as it is able to hydroxylate L-tyrosine, phenol, 3-hydroxyphenylacetate, hydroquinone, p-cresol [13].

The production of L-DOPA is mainly focused on the engineering of a strain that could accumulate L-tyrosine. This means channeling the carbon flux towards L-tyrosine production through engineering of the aromatic amino acid pathway. Bioprocess production of aromatic amino acids from renewable resources like glucose and glycerol is likely to replace the chemical synthesis method
[14-17]. L-Tyrosine has been produced in lower quantities as compared to other aromatic amino acids because of its fewer applications in the industrial settings [18, 19]. Combinatorial and rational approaches have been used to optimize the production of aromatic amino acids. Rational approaches for enhancing aromatic amino acids production have seen channeling carbon flux towards end products through the overexpression of pathway enzymes, use of feedback-resistant enzymes, and deregulation of regulators [20-24]. The microbial production of these aromatic amino acids from glucose begins with the condensation of PEP and E4P to form DAHP by the DAHP synthase isoenzymes aroF, aroG and aroH [25, 26]. In the quest to optimize the production of L-tyrosine and other aromatic amino acids, a balance between carbon flux toward TCA cycle and the shikimate pathway is recommended to enhance efficient cell growth and product formation $[27,28]$.

The production of L-DOPA is hinged on the availability of L-tyrosine and an efficient enzyme to catalyze the hydroxylation process. Thus, the main objective of this study was to metabolically engineer an L-tyrosine-producing strain through the enhancement of the shikimate pathway for higher L-DOPA production. The efficiency of $h p a B$ was also enhanced through error-prone PCR mutagenesis. Finally, efficient de novo production of L-DOPA from glucose and glycerol was achieved.

\section{Materials and methods}

\section{Bacterial strains and plasmids}

Escherichia coli BL21 (DE3) was used for vector expression while Escherichia coli JM109 was used for recombinant plasmids construction. Bacteria strains and plasmids used in this study are listed in Tables 1 and 2.

\section{Construction of recombinant plasmids}

Standard operating measures were adopted for PCR, DNA purifications, enzyme digestions, ligations,

Table 1 Strains

\begin{tabular}{|c|c|c|}
\hline Strains & Description & References \\
\hline E. coli BL21 & Expression host, $\mathrm{F}^{-}$ompT gal dem hsdS $\mathrm{B}_{\mathrm{B}}\left(\mathrm{r}_{\mathrm{B}}^{-} \mathrm{m}_{\mathrm{B}}^{-}\right) \lambda(\mathrm{DE} 3)$ & Novagen \\
\hline E. coli JM109 & $\begin{array}{l}\text { Cloning host, endA1 glnV44thi-1 relA1 gyrA96 recA1 mcrB }{ }^{+} \triangle(\text { lac-proAB) glnV44 e14-[F'traD36 proAB } \\
\left.\left.\text { lacl }{ }^{9} \text { lacZ } \triangle M 15\right] \text { hsdR17( } r_{K}^{-} m^{+} \mathrm{K}\right)\end{array}$ & Stratagene \\
\hline E. coli LP-1 & E. coli BL21, $\Delta$ tyrR & This study \\
\hline E. coli LP-2 & E. coli LP-1, $\Delta p t s G, \Delta c r r$ & This study \\
\hline E. coli LP-3 & E. coli LP-2, $\Delta$ tyrR, $\Delta p t s G, \Delta c r r, T_{7}$-galP-glk & This study \\
\hline E. coli LP-4 & E. coli LP-3, $\Delta$ tyrR, $\Delta p t s G, \Delta c r r, T_{7}-g a l P-g l k, \Delta p h e A$ & This study \\
\hline E. coli LP-5 & E. coli LP-4, $\Delta t y r R, \Delta p t s G, \Delta c r r, T_{7}-g a l P-g l k, \Delta p h e A, T_{7}$-aroG ${ }^{f b r}-t y r A^{f b r}$ & This study \\
\hline E. coli LP-6 & E. coli LP-5, $\Delta t y r R, \Delta p t s G, \Delta c r r, T_{7}$-galP-glk, $\Delta p h e A, T_{7}$-aroG ${ }^{f b r}-t y r A^{f o r}, T_{7}-t k t A, T_{7}-p p s A$ & This study \\
\hline E. coli LP-7 & E. coli LP-6, $\Delta t y r R, \Delta p t s G, \Delta c r r, \mathrm{~T}_{7}$-galP-glk, $\Delta p h e A, \mathrm{~T}_{7}$-aroG ${ }^{f b r}-t y r A^{f b r}, \mathrm{~T}_{7}-t k t A, \mathrm{~T}_{7}-p p s A, \Delta p y k F A$ & This study \\
\hline
\end{tabular}


Table 2 Plasmids

\begin{tabular}{|c|c|c|}
\hline Plasmids & Description & References \\
\hline pRSFDuet & An expression vector, RSF ori, T7lac promoter, lacl gene, Kan', two MCS & Novagene \\
\hline pRSFDuet-hpaB-hpaC & pRSFDuet containing E. coli BL21 hpaBC & This study \\
\hline pETM6 & $\begin{array}{l}\text { An expression vector, T7 promoter/lac operator, pBR322-derived ColE1 replicon, lacl gene, } \\
\text { Ampr }^{r}\end{array}$ & Novagene \\
\hline pCDFDuet-1 & An expression vector, T7lac promoter, CloDF13-derived CDF replicon, lacl gene & Novagene \\
\hline pCDFDuet-1-aro ${ }^{\mathrm{fbr}}-t y r A^{\mathrm{fbr}}$ & pCDFDuet-1 containing E. coli BL21 aroG ${ }^{\mathrm{fbr}}$ and tyrA $\mathrm{A}^{\mathrm{fbr}}$ & {$[60]$} \\
\hline pCas & RepA101(Ts) ori, Kan', Pcas-cas9, ParaC-Red, lacla & {$[61]$} \\
\hline pTarget & sgRNA plasmid, pMB1 ori, Spe & {$[61]$} \\
\hline
\end{tabular}

and plasmid extractions. Primers used in this study are listed in Additional file 1: Table S1. Target genes (hpaBC, galP, glk, ppsA, and $t k t A$ ) were amplified from E. coli BL21 (DE3) genome. HpaB was amplified with primers pR01/pR02 and cloned into BamHI/HindIIIdigested pRSFDuet-1 using ligation-independent cloning system. The ligation product was transformed into JM109 and verified by colony PCR and Sanger sequencing by the primers verpR01/verpR02. The resulting plasmid was named pRSFDuet-1-HpaB. HpaC was amplified with pR03/pR04 and cloned into NdeI/KpnIdigested pRSFDuet-1-HpaB using ligation-independent cloning method. Verification of positive colonies was done by colony PCR and Sanger sequencing with the primers verpR04/verpR05. The resulting plasmid was named pRSFDuet-1-HpaB-HpaC. Plasmid pETM6galP-glk-ppsA-tktA was constructed as already discussed [29]. They were joined in a pseudo-operon configuration using the isocaudamal enzymes $X m a \mathrm{JI}$, $B c u I$, and SalI (Fig. 1). Feedback-resistant mutants of aroG and tyrA generated through directed-site mutagenesis was a gift from our lab.

\section{Gene editing}

In this study genes tyrR, ptsG, crr, pheA, and $p y k F$ were inactivated using the CRISPR-Cas9 system. The twoplasmid system in which the Cas9 gene and sgRNA directing it to the target site, separated in the pCas and pTarget series, was applied for the inactivation of genes. E. coli competent cells harboring pCas were prepared as previously described [30-32]. For $\lambda$-Red induction, arabinose was added to the culture and cultured at $30{ }^{\circ} \mathrm{C}$. Competent cells were mixed with pTarget and donor genes and electroporated. The edited colony was cured of pTarget by inducing with IPTG while pCas9 was cured by culturing strains at $42{ }^{\circ} \mathrm{C}$. Single guide RNAs (sgRNAs) designed for this study are listed in Additional file 1: Table S2.

\section{Directed evolution}

Error-prone PCR was used to generate the randomly mutated pRSFDuet-HpaB library using GeneMorph II Random Mutagenesis Kit (Stratagene) with $h p a B$ as the template. The $50 \mu \mathrm{L}$ PCR mixture composing of $45 \mathrm{ng}$ of the template was prepared as recommended by the

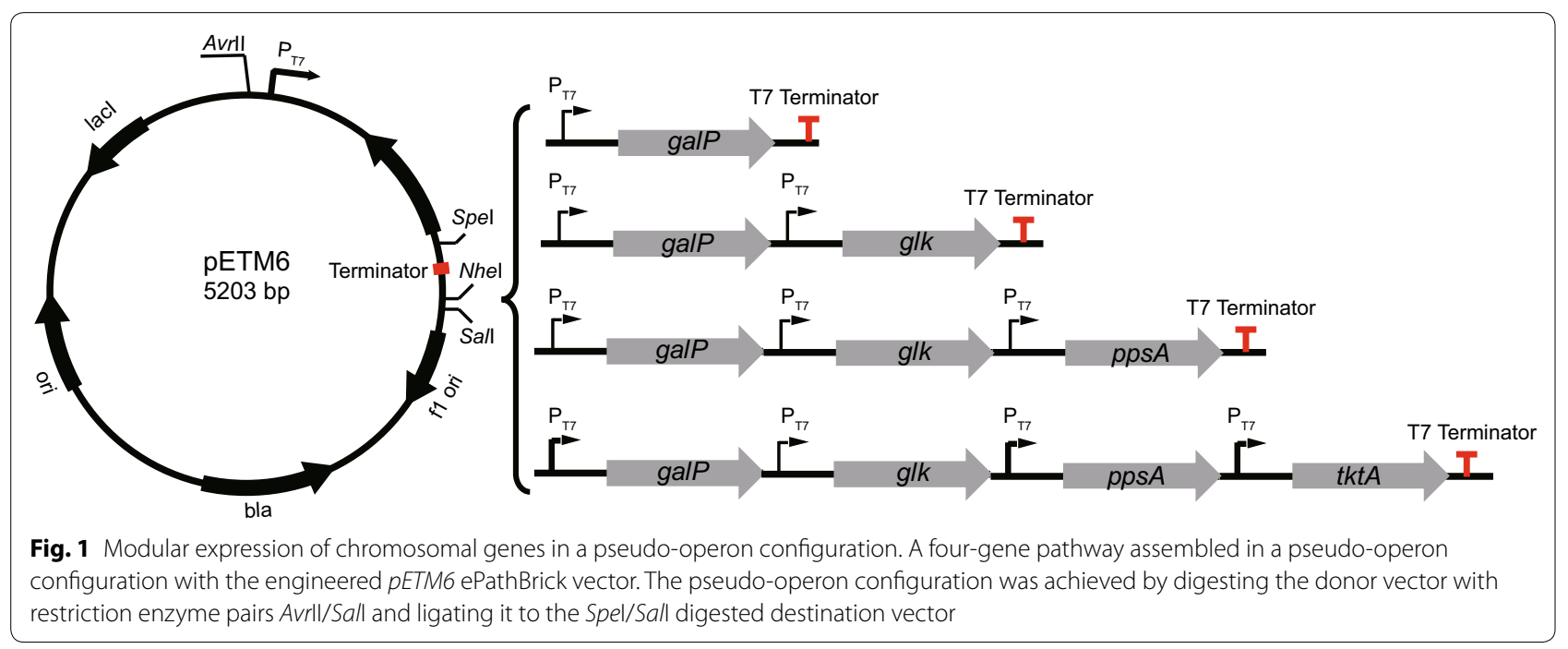


supplier. E. coli BL21 was used for transformation to enhance nick-repair and protein expression. Single colonies from the mutant library were picked with a sterile toothpick and incubated in separate wells of a deep well plate. Incubation was done at $30^{\circ} \mathrm{C}$ and $220 \mathrm{rpm}$ for $48 \mathrm{~h}$. After $48 \mathrm{~h}$, strains that exhibited darker coloration were selected for the subsequent rounds of screening. Enzymatic activity was determined by measuring the quantity of L-DOPA produced after $48 \mathrm{~h}$ of fermentation. For site-directed mutagenesis, primers (sense and antisense) designed for the plasmid pRSFDuet-HpaB that bears mutant sites were used for the amplification in PCRbased site-saturation mutagenesis. Parental methylated and hemimethylated plasmids were digested with $D p n \mathrm{I}$ and transformed into E. coli BL21 for nick-repair. Mutant libraries were confirmed by colony PCR and Sanger sequencing before transforming them into a BL21 strain of $E$. coli again for protein expression.

\section{Shake flask L-DOPA production}

Recombinant strains were routinely cultivated in LB medium $(10 \mathrm{~g} / \mathrm{L}$ tryptone, $5 \mathrm{~g} / \mathrm{L}$ yeast extract, $10 \mathrm{~g} / \mathrm{L}$ $\mathrm{NaCl})$ or $\mathrm{SOB}$ medium $(20 \mathrm{~g} / \mathrm{L}$ tryptone, $5 \mathrm{~g} / \mathrm{L}$ yeast extract, $0.5 \mathrm{~g} / \mathrm{L} \mathrm{NaCl}, 2.5 \mathrm{mM} \mathrm{KCl}$ and $10 \mathrm{mM} \mathrm{MgCl}{ }_{2}$ ). Various concentrations of antibiotics (ampicillin $100 \mu \mathrm{g} /$ $\mathrm{mL}$, kanamycin $40 \mu \mathrm{g} / \mathrm{mL}$, spectinomycin $40 \mu \mathrm{g} / \mathrm{mL}$ ) were added as required. For L-DOPA production, a single colony was inoculated in $5 \mathrm{~mL}$ of LB medium and cultured at $37{ }^{\circ} \mathrm{C}$ in a rotary shaker at $200 \mathrm{rpm}$. The overnight seed culture was inoculated in $50 \mathrm{~mL}$ fermentation medium with a starting $\mathrm{OD}_{600}$ of 0.1 . The fermentation medium of $\mathrm{pH} 7$ was composed of $7 \mathrm{~g} / \mathrm{L}$ yeast extract, $7.5 \mathrm{~g} / \mathrm{L}\left(\mathrm{NH}_{4}\right)_{2} \mathrm{SO}_{4}, 2 \mathrm{~g} / \mathrm{L} \mathrm{KH_{2 }} \mathrm{PO}_{4}, 3 \mathrm{~g} / \mathrm{L} \mathrm{K}_{2} \mathrm{HPO}_{4} \cdot 3 \mathrm{H}_{2} \mathrm{O}$, $1 \mathrm{~g} / \mathrm{L} \mathrm{MgSO}_{4} \cdot 7 \mathrm{H}_{2} \mathrm{O}, 10 \mathrm{~g} / \mathrm{L}$ glucose, $5 \mathrm{~g} / \mathrm{L}$ glycerol, $0.45 \mathrm{~g} / \mathrm{L}$ ascorbic acid. The final cultures were incubated at $37{ }^{\circ} \mathrm{C}$ for $48 \mathrm{~h}$ at $220 \mathrm{rpm}$. IPTG was added as an inducer at a concentration of $0.1 \mathrm{mM}$ after $3 \mathrm{~h}$.

\section{L-DOPA production in a 5-L bioreactor}

The fed-batch culture was conducted in a 5 -L fermenter containing $3-\mathrm{L}$ of fermentation medium with a starting $\mathrm{OD}_{600}$ of 0.4. The fermentation medium of $\mathrm{pH} 7.0$ contains $(\mathrm{g} / \mathrm{L}): 7 \mathrm{~g} / \mathrm{L}$ yeast extract, $7.5 \mathrm{~g} / \mathrm{L}\left(\mathrm{NH}_{4}\right)_{2} \mathrm{SO}_{4}, 2 \mathrm{~g} / \mathrm{L}$ $\mathrm{KH}_{2} \mathrm{PO}_{4}, 3 \mathrm{~g} / \mathrm{L} \mathrm{K}_{2} \mathrm{HPO}_{4} \cdot 3 \mathrm{H}_{2} \mathrm{O}, 1 \mathrm{~g} / \mathrm{L} \quad \mathrm{MgSO}_{4} \cdot 7 \mathrm{H}_{2} \mathrm{O}$, $1.1 \mathrm{~g} / \mathrm{L}$ citric acid monohydrate, $0.1 \mathrm{~g} / \mathrm{L}$ Thiamine $\cdot \mathrm{HCl}$, $25 \mathrm{~g} / \mathrm{L}$ glucose, $10 \mathrm{~g} / \mathrm{L}$ glycerol, $0.45 \mathrm{~g} / \mathrm{L}$ ascorbic acid, and $1 \mathrm{~mL} / \mathrm{L}$ of trace element solution. Trace elements solution was composed of $\mathrm{Fe}(\mathrm{III})$ citrate $100 \mathrm{~g} / \mathrm{L}, \mathrm{ZnCl}_{3}$ $18 \mathrm{~g} / \mathrm{L}, \mathrm{MnSO}_{4} \cdot \mathrm{H}_{2} \mathrm{O} 14.64 \mathrm{~g} / \mathrm{L}, \mathrm{CuSO}_{4} \cdot 5 \mathrm{H}_{2} \mathrm{O} 0.75 \mathrm{~g} / \mathrm{L}$, $\mathrm{Na}_{2} \mathrm{MoO}_{4} \cdot 2 \mathrm{H}_{2} \mathrm{O} 2 \mathrm{~g} / \mathrm{L}, \mathrm{CaCl}_{2} \cdot 2 \mathrm{H}_{2} \mathrm{O} 2 \mathrm{~g} / \mathrm{L}, \mathrm{H}_{3} \mathrm{BO}_{3}$ $3.0 \mathrm{~g} / \mathrm{L}, \mathrm{CoCl}_{2} \cdot 6 \mathrm{H}_{2} \mathrm{O} 2.5 \mathrm{~g} / \mathrm{L}, \mathrm{NiSO}_{4} \cdot 6 \mathrm{H}_{2} \mathrm{O} 2.5 \mathrm{~g} / \mathrm{L}$ and $\mathrm{HCl} 100 \mathrm{~mL}$. The feed solution was composed of $0.45 \mathrm{~g} / \mathrm{L}$ ascorbic acid, $3 \mathrm{~g} / \mathrm{L} \mathrm{MgSO}_{4} \cdot 7 \mathrm{H}_{2} \mathrm{O}, 10 \mathrm{~g} / \mathrm{L}$ yeast extract and $50 \%(\mathrm{w} / \mathrm{w})$ glycerol. The $\mathrm{pH}$ was kept at $\mathrm{pH} 7.0$ by automatic titration of $10 \mathrm{~mol} / \mathrm{L} \mathrm{NH}_{4} \mathrm{OH}$ and $20 \%$ (V/V) $\mathrm{H}_{2} \mathrm{SO}_{4}$ with an airflow of $3 \mathrm{~L} / \mathrm{min}$. Dissolved oxygen was kept at $40 \%$ by regulating the speed from 500 to $900 \mathrm{rpm}$ to enhance the efficient supply of oxygen. IPTG was added as an inducer at a concentration of $0.1 \mathrm{mmol} / \mathrm{L}$ after $12 \mathrm{~h}$. Samples were periodically withdrawn and the following parameters measured: $\mathrm{OD}_{600}$, tyrosine concentration, L-DOPA concentration, residual glucose concentration, and melanin concentration. Fermentation experiments were carried out in triplicate.

\section{Analytical methods}

Quantification of L-DOPA and L-tyrosine were done with a cell-free supernatant of broth and filtered with $0.2 \mu \mathrm{m}$-pore-size polytetrafluoroethylene membrane syringe filters for use in an Agilent HPLC 1260 Series comprising a quaternary pump, an auto-sampler, and a UV detector. Samples were separated on a Phenomenex Gemini $\mathrm{C}_{18}$ column. The mobile phase consisted of $0.08 \%$ formic acid and acetonitrile. It was filtered and degassed prior to its usage. The column temperature was maintained at $30{ }^{\circ} \mathrm{C}$ while detection was monitored at a wavelength of $280 \mathrm{~nm}$. The injection volume of samples was set at $10 \mu \mathrm{L}$ with a flow rate of $1 \mathrm{~mL} / \mathrm{min}$. A standard curve was constructed from serial dilutions of a standard stock solution. Melanin production was determined by measuring absorbance at $400 \mathrm{~nm}$ from culture supernatants. One $\mathrm{OD}_{400}$ unit is equivalent to $0.066 \mathrm{~g} / \mathrm{L}$ of eumelanin [33].

\section{Results \\ Deletion of the tyrR transcriptional regulator and altering substrate transport}

The inactivation of the tyrR gene has proven to enhance the production of aromatic compounds [34-36]. To increase the production of L-DOPA, tyrR was deleted to produce LP-1 (Table 1) relieving the repression effect on L-tyrosine accumulation. LP-1 could produce $196.21 \mathrm{mg} / \mathrm{L}$ of L-DOPA compared to $119.61 \mathrm{mg} / \mathrm{L}$ of the wild-type strain from $10 \mathrm{~g} / \mathrm{L}$ of glucose supplemented with $5 \mathrm{~g} / \mathrm{L}$ glycerol, representing a 1.64-fold increment. To increase the accumulation of phosphoenolpyruvate (PEP), a major component in the production of $\mathrm{L}$-tyrosine and other aromatic amino acids, the phosphotransferase system (PTS) has been a major knock-out target. The PTS not only competes with the accumulation of PEP but also regulates or inhibits other non-PTS protein in an inducer exclusion regulatory mechanism [3740]. To enhance the translocation of the two substrates, ptsG and crr were also deleted to get strain LP-2 which resulted in $259.83 \mathrm{mg} / \mathrm{L}$ of L-DOPA production (Table 3). To enhance glucose transportation in the $\mathrm{PTS}^{-}$strain, a 
Table 3 Shake flask L-DOPA production in engineered $E$. coli BL21 strains

\begin{tabular}{|c|c|c|c|c|}
\hline Strain & Modification in the BL21 strain & $\mathrm{OD}_{600}$ & Tyrosine (mg/L) & L-DOPA (mg/L) \\
\hline $\begin{array}{l}\text { E. coli BL21 (pRSF- } \\
\text { Duet-1-hpaBC) }\end{array}$ & & $6.2 \pm 0.1$ & $324.0 \pm 3.4$ & $119.6 \pm 1.4$ \\
\hline BL21 LP-1 & E. coli BL21- $\Delta$ tyrR & $6.4 \pm 0.1$ & $274.9 \pm 5.6$ & $196.2 \pm 1.2$ \\
\hline BL21 LP-2 & E. coli BL21- $\Delta$ tyrR- $\Delta p t s G-\Delta c r r$ & $6.2 \pm 0.0$ & $354.2 \pm 21.5$ & $259.8 \pm 11.2$ \\
\hline$B L 21$ LP-3 & E. coli BL21- $\Delta t y r R-\Delta p t s G-\Delta c r r-P_{T 7}-g a l P-g / k$ & $5.9 \pm 0.1$ & $362.1 \pm 44.6$ & $318.9 \pm 12.3$ \\
\hline BL21 LP-4 & E. coli BL21- $\Delta t y r R-\Delta p t s G-\Delta c r r-P_{T 7}-g a l P-g l k-\Delta p h e A$ & $5.8 \pm 0.1$ & $421.0 \pm 6.4$ & $411.7 \pm 2.3$ \\
\hline BL21 LP-5 & E. coli BL21- $\Delta t y r R-\Delta p t s G-\Delta c r r-P T 7-g a l P-g l k-\Delta p h e A-P_{T 7}-a r o G^{f b r}-t y r A^{f b r}$ & $5.8 \pm 0.0$ & $364.0 \pm 6.1$ & $432.0 \pm 4.1$ \\
\hline BL21 LP-6 & $\begin{array}{l}\text { E. coli BL21- } \Delta t y r R-\Delta p t s G-\Delta c r r-P T 7-g a l P-g l k-\Delta p h e A-P_{T 7}-a r o G^{f b r}-t y r A^{f b r}{ }_{-} \\
\quad P_{T 7} \text {-galp-glk-ppsA-tktA }\end{array}$ & $5.8 \pm 0.0$ & $392.3 \pm 32.4$ & $548.7 \pm 10.2$ \\
\hline BL21 LP-7 & $\begin{array}{l}\text { E. coli BL21- } \Delta t y r R-\Delta p t s G-\Delta c r r-P T 7-g a l P-g l k-\Delta p h e A-P_{T 7}-a r o G^{f b r}-t y r A^{f b r}- \\
\quad P_{T 7}-g a l p-g l k-p p s A-t k t A-p y k F A\end{array}$ & $5.5 \pm 0.2$ & $461.7 \pm 12.0$ & $593.9 \pm 18.4$ \\
\hline
\end{tabular}

PEP-independent glucose transportation and phosphorylation system have successfully been used to replace PTS [41-43]. L-DOPA production reached $318.89 \mathrm{mg} / \mathrm{L}$ when galP and $g l k$ were expressed under a T7 promoter in LP-3 strain (Table 3).

\section{Deletion of the competing pathway}

Production of L-tyrosine has always been in competition with L-phenylalanine. In order to decrease the level of L-phenylalanine production, Patnaik et al. used an L-phenylalanine auxotroph to produce an unprecedented quantity of L-tyrosine [44]. Therefore, an L-phenylalanine auxotroph was developed by deleting pheA to produce strain LP-4 (Table 1). LP-4 strain produced $411.72 \mathrm{mg} / \mathrm{L}$ of L-DOPA representing a 1.29-fold increment.

\section{Deregulation of transcriptional regulators and precursors accumulation}

L-DOPA production reached to $432.01 \mathrm{mg} / \mathrm{L}$ when aroGfbr and tyrAfbr were expressed under a T7 in LP-5 strain. Overexpression of the genes $t k t A$ and $p p s A$ in $E$. coli strains has produced $10 \%$ and $30 \%$ increment in the L-tyrosine production respectively [17]. Expressing the two enzymes under the $T_{7}$ Promoter in a pseudo-operon configuration, which has shown to enhance the expression level of enzymes in a modular configuration, strain LP-6 could produce $548.67 \mathrm{mg} / \mathrm{L}$ of L-DOPA from overexpressed ppsA and $t k t A$ (Table 3). Overexpression of pathway enzymes to increase carbon flux in $E$. coli cells tends to increase the production of acetate, which negatively affects their cellular health during long hours of fermentation [45]. It has also been reported earlier that the deletion of pyruvate kinase in a $\mathrm{PTS}^{-}$could enhance shikimic acid production [46]. Therefore, $p y k F$ was deleted in LP-6, which got a striking improvement in the accumulation of L-DOPA $593.9 \mathrm{mg} / \mathrm{L}$ in LP-7.

\section{Directed evolution of $H p a B$}

Error-prone PCR was applied to pRSFDuet-1-hpaB to achieve $h p a B$ variants after which site-directed saturation mutagenesis was used to confirm the randomly generated mutants. Sequence analysis of mutant libraries showed alterations in different amino acids. Using the production of L-DOPA as the primary screening method, G295R, G295A, and L411M were selected for increased efficiency. These three variants showed an improved L-DOPA production as compared to the wild-type. L-DOPA production reached $362.34 \mathrm{mg} / \mathrm{L}, 346.57 \mathrm{mg} / \mathrm{L}$ and $305.76 \mathrm{mg} / \mathrm{L}$ in these mutants representing a 3.03-, 2.9- and 2.56-fold increment respectively. In order to increase L-DOPA production, the three $h p a B$ mutants were expressed in LP-7 to produce LP-8 (G295R), LP-9 (G295A) and LP-10 (L411M). L-DOPA production reached $691.24 \mathrm{mg} / \mathrm{L}, 658.48 \mathrm{mg} / \mathrm{L}$ and $621.71 \mathrm{mg} / \mathrm{L}$ respectively (Fig. 2). Cell growth $\left(\mathrm{OD}_{600}\right)$ of these strains, were $5.38 \pm 0.2,5.46 \pm 0.1$, and $5.41 \pm 0.1$ respectively.

\section{Enhanced L-DOPA production in a 5-L bioreactor}

To increase L-DOPA titers and yield to satisfy industrial potential, a $5 \mathrm{~L}$ fermenter was used to optimize the L-DOPA production. The exponential-to-DO-stat feeding strategy of fed-batch fermentation process was adopted to maintain a $12-25 \mathrm{~g} / \mathrm{L}$ of the substrate for product synthesis while maintaining the DO at an appreciable level. E. coli LP-8 was used in the fed-batch fermentation process. The $\mathrm{OD}_{600}$ reached 79 after the 48 - $\mathrm{h}$ fermentation (Fig. 3). The total L-DOPA yield after $48 \mathrm{~h}$ fermentation reached $25.53 \mathrm{~g} / \mathrm{L}$ (Fig. 3). Munoz et al. and Wei et al. reported total L-tyrosine conversion to L-DOPA after $40 \mathrm{~h}[47,48]$ but our engineered strain could produce an excess of $40.42 \mathrm{~g} / \mathrm{L}$ of L-tyrosine after the fermentation process which demonstrates the production capability of our engineered strain (Fig. 3). It 


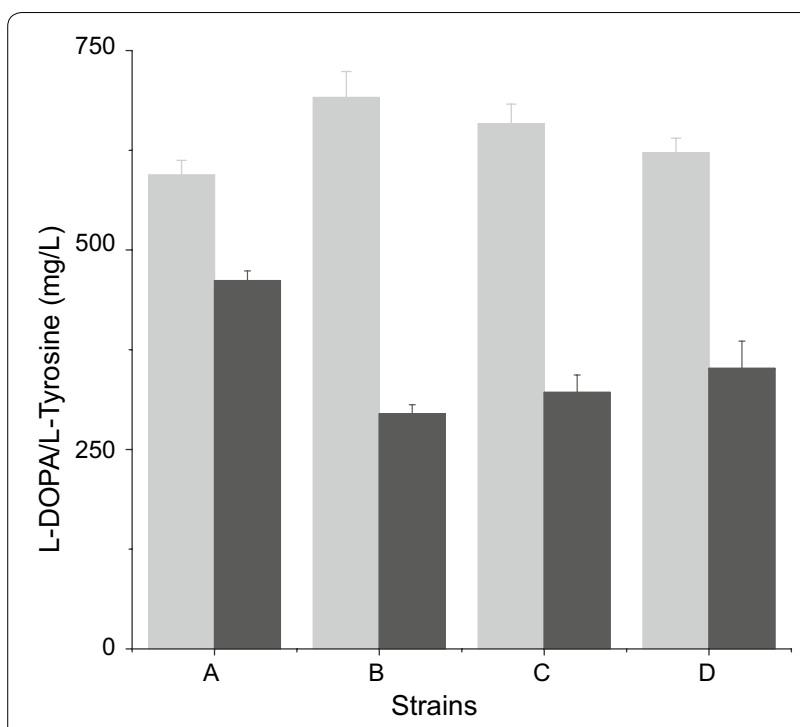

Fig. 2 L-DOPA production from $h p a B$ randomly generated mutants. $H p a B$ variants showed an increased L-DOPA production compared to the wild-type hpaB. White bars: L-DOPA; Black bars: L-tyrosine. A: E. coli LP-7; B. E. coli LP-8; C. E. coli LP-9; B. E. coli LP-10

was also observed that the rate of oxidation of L-DOPA to eumelanin increases as the time increases which led to the darkening of the fermentation broth. This resulted in a reduction of $\mathrm{L}-\mathrm{DOPA}$ after the fermentation process.

\section{Discussion}

Microbial fermentation for L-DOPA production has previously been focused on the catalyzation of L-tyrosine by tyrosinase [7] or through catechol and pyruvate from tyrosine phenol-lyase (TPL) [49-51]. The de novo production of this anti-Parkinson drug is mainly dependent on the hydroxylation of L-tyrosine by $h p a B C$ with glucose or glycerol as the sole carbon source. This makes L-tyrosine an integral part of L-DOPA production. Hence, the main objective of this work was to improve the supply of L-tyrosine through the enhancement of the shikimate pathway for L-tyrosine production. A one-step fermentation process with glucose or glycerol as a substrate is now gaining grounds. This process is meant to economize L-DOPA production via microbial fermentation. The maiden de novo production of L-DOPA in an engineered E. coli was accomplished by Munoz et al. when they produced $1.51 \mathrm{~g} / \mathrm{L}$ of L-DOPA in a $1 \mathrm{~L}$ bioreactor [47]. Later Wei et al. achieved a 5.74-fold increment in L-DOPA production via a metabolic engineering and MAGE strategy [48]. A. Das et al. recently achieved a 1.44-fold increment in the anti-Parkinson drug production from the previous work when they used glycerol as the substrate for L-tyrosine production [52]. To achieve a higher L-DOPA production, this current study focused on the enhancement

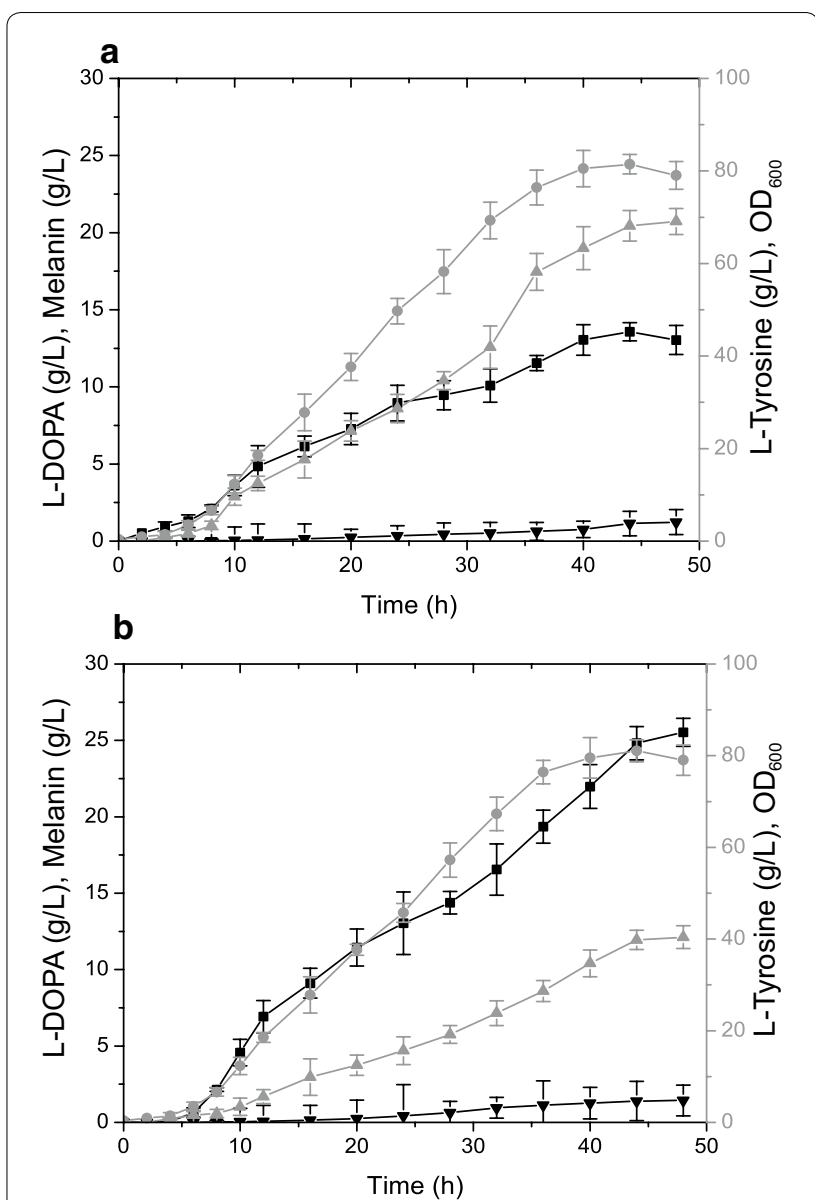

Fig. 3 Fed-batch L-DOPA production in a $5 \mathrm{~L}$ bioreactor. Metabolites and cell growth during fed-batch fermentation are indicated. $\mathbf{a} E$. coli LP-7; b E. coli LP-8. Symbols: Black squares: L-DOPA concentration; Gray Up-triangles: L-tyrosine concentration; Black Down-triangles: Melanin concentration; Gray circles: $\mathrm{OD}_{600}$

of the shikimate pathway for L-tyrosine accumulation. The enzyme responsible for hydroxylating L-tyrosine to L-DOPA went through the simple powerful Darwinian principle of mutation and selection to enhance its activity. Relying on these two strategies we were able to accumulate a 2.04-fold increment in L-DOPA production against the previous study.

Active pharmaceutical ingredients production over the years have all relied on the accumulation of their respective precursors. This has been achieved via metabolic engineering to channel flux towards that precursor production. The de novo biosynthesis of L-DOPA is dependent on the accumulation of L-tyrosine through the enhancement of the shikimate pathway. Major metabolic bottle-necks for higher aromatic amino acids production are the accumulation of the two main precursors (PEP and E4P), the effects of transcriptional regulators and feedback inhibition on some key enzymes [20-24]. 


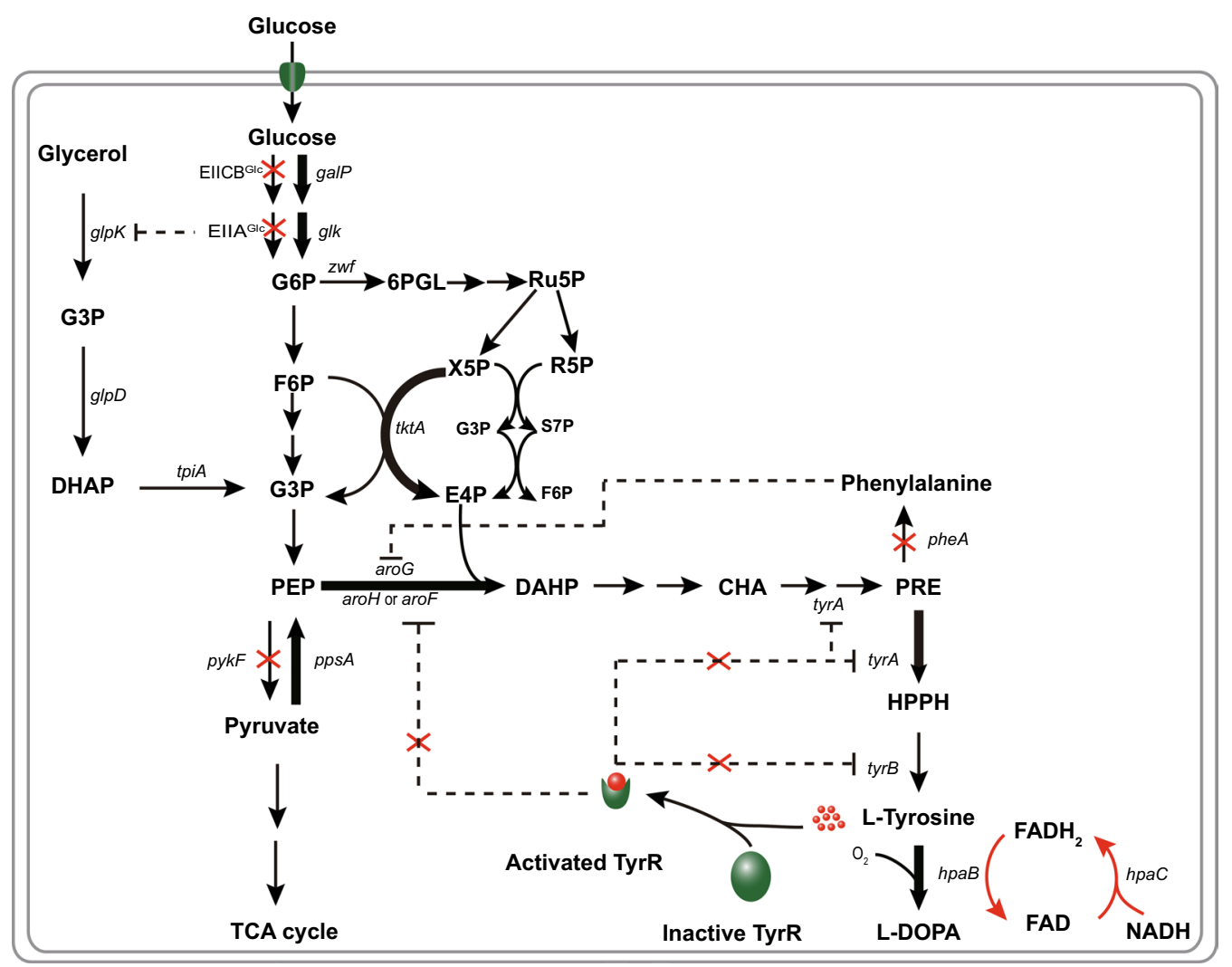

Fig. 4 Proposed metabolic pathway for the biosynthesis of L-DOPA in Escherichia coli. Double arrow indicates more enzyme reactions; Dashed lines indicate transcriptional inhibition; X indicates deleted genes; Bold arrow indicates overexpressed gene; galP galactose permease; glk glucokinase; G6P glucose-6-phosphate; F6P fructose-6-phosphate; G3P glyceraldehyde 3-phosphate; PEP phosphoenolpyruvate; tkkA transketolase A; E4P erythrose 4-phosphate; 6PGL 6-phospho D-glucono-1,5-lactone; Ru5P ribulose-5-phosphate, X5P xylulose-5-phosphate, R5P ribose-5-phosphate; S7P Sedoheptulose 7-phosphate; DAHP 3-deoxy-D-arabino-heptulosonate-7-phosphate synthase; CHA chorismate; PRE prephenate; HPPH 4 hydroxyphenylpyruvate; PHE phenylalanine; $p p s A$ phosphoenolpyruvate synthase; tyrR tyrosine repressor; TCA tricarboxylic acid; tyrA chorismate mutase-prephenate dehydrogenase; tyrB tyrosine aminotransferase; aroF DAHP synthase feedback inhibited by tyrosine; aroG DAHP synthase feedback inhibited by phenylalanine; aroH DAHP synthase feedback inhibited by tryptophan; L-DOPA 3,4-dihydroxyphenyl-L-alanine; $9 / p K \mathrm{glycerol}$ kinase; glpD glycerol-3-phosphate dehydrogenase; tpiA triosephosphate isomerase; G3P glycerol-3-phosphate; DHAP dihydroxyacetone phosphate; EllCB ${ }^{\mathrm{GlC}}$ glucose-specific IICB component; EllA ${ }^{\text {GlC }}$ glucose-specific IIA component; pheA chorismate mutase/prephenate dehydratase

To overcome these metabolic huddles, key competing pathway enzymes have been deleted to enhance the availability of the two main precursors, while expressing feedback resistant enzymes and overexpression of pathway enzymes. The deletion of $t y r R$ has remained a major target in the metabolic engineering of $E$. coli for L-tyrosine production and its deletion has always proven positive for L-tyrosine accumulation. We, therefore, deleted tyrR which saw a 1.64-fold increment in L-DOPA synthesis. A major drawback for glucose metabolism in microbial fermentation is the usage of PEP as a phosphate donor by the PTS for phosphorylation and translocation of glucose [53]. Glycerol also has a limiting factor which could be attributed to the inducer exclusion effect of EIIA ${ }^{\text {Glc }}$ on glycerol kinase $(g l p K)$ [54]. The inactivation of the PTS
(ptsG/crr) has been suggested to enhance the accumulation of PEP while also relieving the inducer exclusion effect on $g l p K$.

Glycerol with its high reducing potential can increase the availability of NADH, a major cofactor for $h p a C$ reduction of flavin for subsequent hydroxylation of the substrate, L-tyrosine by hpaB (Fig. 4). The use of glycerol as a feed in the fed-batch fermentation process enhanced the production of L-DOPA as Lee and Xun through the use of glycerol saw about a 2.0-fold increase in L-DOPA production [13]. It also ensured a reduction in acetate production which would have hindered cell growth. Glucose-6-phosphate 1-dehydrogenase $(z w f)$ is a popular knockout target in the quest to increase flux toward the EMP. But its deletion has been shown to have 
a negative impact on NADPH production, an essential co-factor in the L-DOPA biosynthesis from the pentose phosphate pathway [55]. In this work, the deletion of $z w f$ saw a reduction in L-DOPA production (data not showed), which made us ignore its usage. In E. coli, AroG which is inhibited by L-Phe (a major competing pathway in L-tyrosine production) contributes to approximately $80 \%$ of total DAHP synthase activity [56] while tyrA is also feedback inhibited by L-tyrosine. The introduction of feedback-resistant versions of the DAHP synthase $\left(a r o G^{f b r}\right)$ and chorismate mutase $\left(t y r A^{f b r}\right)$ have in the past helped in the accumulation L-tyrosine. Expression of these feedback-resistant forms after the deletion of $p h e A$ saw a striking improvement in L-DOPA production.

The deletion of $p y k F$ results in the accumulation of PEP and the activation of the oxidative route of the PP pathway that enhance the accumulation of E4P and hence resulting in the increased production of aromatic amino acids [57]. To increase PEP/E4P availability we deleted $p y k F$ after which $p p s A$ and $t k t A$ were overexpressed. Production of L-tyrosine was improved which increased the L-DOPA production likewise. Directed evolution which uses the simple powerful Darwinian principles of mutation and selection helps resolve the limitation on how and where to mutate to enhance the activity of an enzyme $[58,59]$. The hydroxylation of L-tyrosine to L-DOPA by $h p a B$ is said to be slow as not all the L-tyrosine produced is being converted to L-DOPA. Enhancement of the catalytic activity through rational evolution process could potentially relieve this bottleneck. The screening of $E$. coli BL21 libraries expressing variant oxygenase component of 4-hydroxyphenylacetate 3-monooxygenase (hpaB) was based on simple colorimetric approach, in which the appearance of the dark-colored Melanin within $48 \mathrm{~h}$ of fermentation served as a good indicator for improved enzymatic activity. This approach could not be deemed appropriate in the selection process but the appearance of dark-colored Melanin could not be achieved in the shortest time without high L-DOPA production. The engineered $E$. coli strain expressing mutant forms (G295R, G295A, L411M) of hpaB saw an improvement in the hydroxylation process.

\section{Conclusion}

Elimination of the tyrR, a transcriptional regulator for L-tyrosine production combined with the deletion of the phosphotransferase system and some key competing pathway enzymes like pheA and $p y k F$ increased L-tyrosine production. Modular expression of pathway enzymes also improved the supply of L-tyrosine. The engineered E. coli strain, LP-8, produced $25.53 \mathrm{~g} / \mathrm{L}$ of L-DOPA from glucose and glycerol in a $5 \mathrm{~L}$ bioreactor. In conclusion, we have been able to successfully engineer an E. coli BL21 strain that could produce L-DOPA from glucose with glycerol as a co-substrate. Also, through an error-prone PCR random mutagenesis, we were able to screen an $h p a B$ that have an improved hydroxylation performance than its wild-type. Though we were able to achieve a higher titer as compared to previous works, we know there are other strategies like $\mathrm{pH}$ and temperature control that when employed could improve the microbial production of this anti-Parkinson drug.

\section{Additional file}

Additional file 1. Additional tables and figures.

\section{Authors' contributions}

EF carried out the experiments and drafted the manuscript. FKA and SZ assisted in plasmid construction and metabolites analysis. GD and JZ participated in designing the study and writing the manuscript. All authors read and approved the final manuscript.

\section{Author details \\ ${ }^{1}$ National Engineering Laboratory for Cereal Fermentation Technology, Jiang- nan University, 1800 Lihu Road, Wuxi 214122, Jiangsu, China. ${ }^{2}$ Key Laboratory of Industrial Biotechnology, Ministry of Education, School of Biotechnology, Jiangnan University, 1800 Lihu Road, Wuxi 214122, Jiangsu, China. ${ }^{3}$ The Key Laboratory of Carbohydrate Chemistry \& Biotechnology, Ministry of Education, School of Biotechnology, Jiangnan University, Wuxi 214122, China. ${ }^{4}$ Jiangsu Provisional Research Center for Bioactive Product Processing Technology, Jiangnan University, 1800 Lihu Road, Wuxi 214122, Jiangsu, China.}

\section{Acknowledgements}

Not applicable.

\section{Competing interests}

The authors declare that they have no competing interests.

\section{Availability of data and materials}

All data generated or analyzed during this study are included in this published article and its additional file.

\section{Consent for publication}

Not applicable.

\section{Ethics approval and consent to participate}

Not applicable.

\section{Funding}

This work was supported by the National Key Research and Development Program of China (2017YFC1600403), the National Natural Science Foundation of China (31670095, 31770097), the Key Research and Development Program of Jiangsu Province (BE2016689), the Fundamental Research Funds for the Central Universities (JUSRP51701A), the Six Talent Peaks Project in Jiangsu Province (2015-JY-005), the National First-class Discipline Program of Light Industry Technology and Engineering (LITE2018-08), the Distinguished Professor Project of Jiangsu Province, and the Chinese Scholarship Council.

\section{Publisher's Note}

Springer Nature remains neutral with regard to jurisdictional claims in published maps and institutional affiliations.

Received: 18 December 2018 Accepted: 16 April 2019

Published online: 25 April 2019 


\section{References}

1. Fahn S. The medical treatment of Parkinson disease from James Parkinson to George Cotzias. Mov Disord. 2015;30:4-18.

2. Nadjar A, Gerfen CR, Bezard E. Priming for L-DOPA-induced dyskinesia in Parkinson's disease: a feature inherent to the treatment or the disease? Prog Neurobiol. 2009;87:1-9.

3. Min K, Park DH, Yoo YJ. Electroenzymatic synthesis of L-DOPA.J Biotechnol. 2010;146:40-4.

4. Nagatsua T, Sawadab M. L-dopa therapy for Parkinson's disease: past, present, and future. Parkinsonism Relat Disord. 2009;15(Suppl 1):S3-8.

5. Sayyed IA, Sudalai A. Asymmetric synthesis of L-DOPA and (R)-selegiline via, $\mathrm{OsO}_{4}$-catalyzed asymmetric dihydroxylation. Tetrahedron. 2004;15:3111-6.

6. Valdés RH, Puzer L, Gomes M, Marques CESJ, Aranda DAG, Bastos ML, Gemal AL, Antunes OAC. Production of L-DOPA under heterogeneous asymmetric catalysis. Catal Commun. 2004;5:631-4.

7. Koyanagi T, Katayama T, Suzuki H, Nakazawa H, Yokozeki K, Kumagai H. Effective production of 3,4-dihydroxyphenyl-L-alanine (L-DOPA) with Erwinia herbicola cells carrying a mutant transcriptional regulator TyrR. J Biotechnol. 2005;115:303-6.

8. Min K, Park K, Park DH, Yoo YJ. Overview on the biotechnological production of L-DOPA. Appl Microbiol Biotechnol. 2015;99:575-84.

9. Garcia-Borron JC, Solano F. Molecular anatomy of tyrosinase and its related proteins: beyond the histidine-bound metal catalytic center. Pigment Cell Res. 2002;15:162-73.

10. Prieto MA, Garcia JL. Molecular characterization of 4-hydroxyphenylacetate 3-hydroxylase of Escherichia coli. A two-protein component enzyme. J Biol Chem. 1994;269:22823-9.

11. Prieto MA, Perez-Aranda A, Garcia JL. Characterization of an Escherichia coli aromatic hydroxylase with a broad substrate range. J Bacteriol. 1993:175:2162-7.

12. Xun L, Sandvik ER. Characterization of 4-hydroxyphenylacetate 3-hydroxylase (HpaB) of Escherichia coli as a reduced flavin adenine dinucleotideutilizing monooxygenase. Appl Environ Microbiol. 2000;66:481-6.

13. Lee J-Y, Xun L. Novel biological process for L-DOPA production from L-tyrosine by P-hydroxyphenylacetate 3-hydroxylase. Biotechnol Lett. 1998;20:479-82.

14. Bongaerts J, Kramer M, Muller U, Raeven L, Wubbolts M. Metabolic engineering for microbial production of aromatic amino acids and derived compounds. Metab Eng. 2001;3:289-300.

15. Ikeda M. Towards bacterial strains overproducing L-tryptophan and other aromatics by metabolic engineering. Appl Biochem Biotechnol. 2006;69:615-26.

16. Leuchtenberger W, Huthmacher K, Drauz K. Biotechnological production of amino acids and derivatives: current status and prospects. Appl Microbiol Biotechnol. 2005;69:1-8.

17. Lutke-Eversloh T, Stephanopoulos G. L-Tyrosine production by deregulated strains of Escherichia coli. Appl Microbiol Biotechnol. 2007:75:103-10.

18. Ikram UH, Ali S. Microbiological transformation of L-tyrosine to 3,4-dihydroxyphenyl L-alanine (L-DOPA) by a mutant strain of Aspergillus oryzae UV-7. Curr Microbiol. 2002;45:88-93.

19. Rosazza J, Foss P, Lemberger M, Sih CJ. Microbiological synthesis of L-DOPA. J Pharm Sci. 1974;63:544-7.

20. Chávez-Béjar MI, Báez-Viveros JL, Martínez A, Bolívar F, Gosset G. Biotechnological production of L-tyrosine and derived compounds. Process Biochem. 2012;47:1017-26.

21. Ikeda M, Okamoto K, Katsumata R. Cloning of the transketolase gene and the effect of its dosage on aromatic amino acid production in Corynebacterium glutamicum. Appl Biochem Biotechnol. 1999;51:201-6.

22. Juminaga D, Baidoo EEK, Redding-Johanson AM, Batth TS, Burd H, Mukhopadhyay A, Petzold CJ, Keasling JD. Modular engineering of L-tyrosine production in Escherichia coli. Appl Environ Microbiol. 2012;78:89-98.

23. Lutke-Eversloh T, Stephanopoulos G. Feedback inhibition of chorismate mutase/prephenate dehydrogenase (TyrA) of Escherichia coli: generation and characterization of tyrosine-insensitive mutants. Appl Environ Microbiol. 2005;71:7224-8.

24. Pittard J, Camakaris H, Yang J. The TyrR regulon. Mol Microbiol. 2005;55:16-26.

25. Berry A. Improving production of aromatic compounds in Escherichia coli by metabolic engineering. Trends Biotechnol. 1996;14:250-6.
26. Frost JW, Draths KM. Biocatalytic syntheses of aromatics from D-glucose: renewable microbial sources of aromatic compounds. Annu Rev Microbiol. 1995:49:557-79.

27. Miller JE, Backman KC, O'Connor MJ, Hatch RT. Production of phenylalanine and organic acids by phosphoenolpyruvate carboxylase-deficient mutants of Escherichia coli. J Ind Microbiol. 1987;2:143-9.

28. Patnaik R, Spitzer RG, Liao JC. Pathway engineering for production of aromatics in Escherichia coli: confirmation of stoichiometric analysis by independent modulation of AroG, TktA, and PpsA activities. Biotechnol Bioeng. 1995;46:361-70

29. Xu P, Vansiri A, Bhan N, Koffas MA. ePathBrick: a synthetic biology platform for engineering metabolic pathways in Escherichia coli. ACS Synth Biol. 2012;1:256-66.

30. Cha JS, Pujol C, Kado Cl. Identification and characterization of a Pantoea citrea gene encoding glucose dehydrogenase that is essential for causing pink disease of pineapple. Appl Environ Microbiol. 1997;63:71-6.

31. Pujol CJ, Kado Cl. Genetic and biochemical characterization of the pathway in Pantoea citrea leading to pink disease of pineapple. J Bacteriol. 2000;182:2230

32. Sharan SK, Thomason LC, Kuznetsov SG, Court DL. Recombineering: a homologous recombination-based method of genetic engineering. Nat Protoc. 2009;4:206-23.

33. Lagunas-Munoz VH, Cabrera-Valladares N, Bolivar F, Martinez A. Optimum melanin production using recombinant Escherichia coli. J Appl Microbiol. 2006;101:1002-8.

34. Na D, Yoo SM, Chung H, Park HS, Park JH, Lee SY. Metabolic engineering of Escherichia coli using synthetic small regulatory RNAs. Nat Biotechnol. 2013;31:170-4

35. Rodriguez A, Martnez JA, Flores N, Escalante A, Gosset G, Bolivar F. Engineering Escherichia coli to overproduce aromatic amino acids and derived compounds. Microb Cell Fact. 2014;13:126.

36. Yakandawala N, Romeo T, Madhyastha S. Metabolic engineering of Escherichia coli to enhance phenylalanine production. Appl Microbiol Biotechnol. 2008;78:283-91.

37. de Boer M, Broekhuizen CP, Postma PW. Regulation of glycerol kinase by enzyme IIIGlc of the phosphoenolpyruvate:carbohydrate phosphotransferase system. J Bacteriol. 1986;167:393-5.

38. Deutscher J, Ake FM, Derkaoui M, Zebre AC, Cao TN, Bouraoui H, Kentache T, Mokhtari A, Milohanic E, Joyet P. The bacterial phosphoenolpy ruvate:carbohydrate phosphotransferase system: regulation by protein phosphorylation and phosphorylation-dependent protein-protein interactions. Microbiol Mol Biol Rev. 2014:78:231-56.

39. Postma PW, Lengeler JW, Jacobson GR. Phosphoenolpyruvate:car bohydrate phosphotransferase systems of bacteria. Microbiol Rev. 1993;57:543-94.

40. Saier MHJ, Novotny MJ, Comeau-Fuhrman D, Osumi T, Desai JD. Cooperative binding of the sugar substrates and allosteric regulatory protein (enzyme IIIGlc of the phosphotransferase system) to the lactose and melibiose permeases in Escherichia coli and Salmonella typhimurium. J Bacteriol. 1983;155:1351-7.

41. Balderas-Hernandez VE, Sabido-Ramos A, Silva P, Cabrera-Valladares N Hernandez-Chavez G, Baez-Viveros JL, Martinez A, Bolivar F, Gosset G. Metabolic engineering for improving anthranilate synthesis from glucose in Escherichia coli. Microb Cell Fact. 2009;8:19.

42. Hernandez-Montalvo V, Martinez A, Hernandez-Chavez G, Bolivar F, Valle F, Gosset G. Expression of galP and glk in a Escherichia coli PTS mutant restores glucose transport and increases glycolytic flux to fermentation products. Biotechnol Bioeng. 2003;83:687-94.

43. Yi J, Draths KM, Li K, Frost JW. Altered glucose transport and shikimate pathway product yields in Escherichia coli. Biotechnol Prog. 2003;19:1450-9.

44. Patnaik R, Zolandz RR, Green DA, Kraynie DF. L-tyrosine production by recombinant Escherichia coli: fermentation optimization and recovery. Biotechnol Bioeng. 2008:99:741-52.

45. Jensen EB, Carlsen S. Production of recombinant human growth hormone in Escherichia coli: expression of different precursors and physiological effects of glucose, acetate, and salts. Biotechnol Bioeng. 1990:36:1-11.

46. Escalante A, Calderon R, Valdivia A, de Anda R, Hernandez G, Ramirez OT, Gosset G, Bolivar F. Metabolic engineering for the production of shikimic acid in an evolved Escherichia coli strain lacking the 
phosphoenolpyruvate: carbohydrate phosphotransferase system. Microb Cell Fact. 2010;9:21.

47. Munoz AJ, Hernandez-Chavez G, de Anda R, Martinez A, Bolivar F, Gosset G. Metabolic engineering of Escherichia coli for improving L-3,4-dihydroxyphenylalanine (L-DOPA) synthesis from glucose. J Ind Microbiol Biotechnol. 2011;38:1845-52.

48. Wei T, Cheng B-Y, Liu J-Z. Genome engineering Escherichia coli for L-DOPA overproduction from glucose. Sci Rep. 2016;6:30080.

49. Ali S, Haq IU, Qadeer MA, Rajoka MI. Double mutant of Aspergillus oryzae for improved production of L-dopa (3,4-dihydroxyphenyl---alanine) from L-tyrosine. Biotechnol Appl Biochem. 2005;42:143-9.

50. Foor F, Morin N, Bostian KA. Production of L-dihydroxyphenylalanine in Escherichia coli with the tyrosine phenol-lyase gene cloned from Erwinia herbicola. Appl Environ Microbiol. 1993;59:3070-5.

51. Surwase SN, Patil SA, Jadhav SB, Jadhav JP. Optimization of L-DOPA production by Brevundimonas sp. SGJ using response surface methodology. Microb Biotechnol. 2012;5:731-7.

52. Das A, Tyagi N, Verma A, Akhtar S, Mukherjee KJ. Metabolic engineering of Escherichia coli W3110 strain by incorporating genome-level modifications and synthetic plasmid modules to enhance L-DOPA production from glycerol. Prep Biochem Biotechnol. 2018;17:671.

53. Carmona SB, Moreno F, Bolivar F, Gosset G, Escalante A. Inactivation of the PTS as a strategy to engineer the production of aromatic metabolites in Escherichia coli. J Mol Microbiol Biotechnol. 2015;25:195-208.
54. Holtman CK, Pawlyk AC, Meadow ND, Pettigrew DW. Reverse genetics of Escherichia coli glycerol kinase allosteric regulation and glucose control of glycerol utilization in vivo. J Bacteriol. 2001;183:3336-44.

55. Williams TC, Averesch NJH, Winter G, Plan MR, Vickers CE, Nielsen LK, Krömer JO. Quorum-sensing linked RNA interference for dynamic metabolic pathway control in Saccharomyces cerevisiae. Metab Eng. 2015;29:124-34.

56. Lin S, Liang R, Meng X, OuYang H, Yan H, Wang Y, Jones GS. Construction and expression of mutagenesis strain of aroG gene from Escherichia coli K-12. Int J Biol Macromol. 2014;68:173-7.

57. Kedar P, Colah R, Shimizu K. Proteomic investigation on the pyk-F gene knockout Escherichia coli for aromatic amino acid production. Enzyme Microb Technol. 2007:41:455-65.

58. Leisola $M$, Turunen O. Protein engineering: opportunities and challenges. Appl Microbiol Biotechnol. 2007;75:1225-32.

59. Stemmer WP. Rapid evolution of a protein in vitro by DNA shuffling Nature. 1994;370:389-91.

60. Wu JJ, Du GC, Zhou JW, Chen J. Metabolic engineering of Escherichia coli for (2S)-pinocembrin production from glucose by a modular metabolic strategy. Metab Eng. 2013:16:48-55.

61. Jiang Y, Chen B, Duan C, Sun B, Yang J, Yang S. Multigene editing in the Escherichia coli genome via the CRISPR-Cas9 system. Appl Environ Microbiol. 2015:81:2506-14.
Ready to submit your research? Choose BMC and benefit from:

- fast, convenient online submission

- thorough peer review by experienced researchers in your field

- rapid publication on acceptance

- support for research data, including large and complex data types

- gold Open Access which fosters wider collaboration and increased citations

- maximum visibility for your research: over 100M website views per year

At BMC, research is always in progress.

Learn more biomedcentral.com/submissions 